\title{
OPIAL'S INEQUALITY FOR ZERO-AREA CONSTRAINT
}

\section{JOCHEN DENZLER}

Abstract. We prove that $\int_{0}^{1}\left|y y^{\prime}\right| \leqslant \frac{1}{4} \int_{0}^{1} y^{\prime 2}$ provided $\int_{0}^{1} y=0$. The nontrivial part is the sharp constant $\frac{1}{4}$. Cases of equality can be abstracted from the proof. This is an (apparently much deeper) variant of a result by Opial, who proved the same estimate under Dirichlet boundary conditions on $y$.

Mathematics subject classification (2000): 26D10, 46E35, 49J35.

Key words and phrases: Opial inequality, sharp constants, rearrangement.

\section{REFERENCES}

[1] PaUl R. BeEsack, On an integral inequality of Z. Opial, Trans. Amer. Math. Soc. 104 (1962), 470-475

[2] H. J. BRASCAMP, E. H. LiEB, Best constants in Young's inequality, its converse, and its generalizations to more than three functions, Adv. in Math. 20 (1976), 151-173

[3] Y. BRENIER, Polar factorization and monotone rearrangement of vector-valued functions, Comm. Pure Appl. Math. 44 (1991), 375-417

[4] R. C. Brown, A. M. FinK, D. B. Hinton, Some Opial, Lyapunov and De la Vallée Poussin inequalities with nonhomogeneous boundary conditions, J. Inequal. Appl. 5 (2000), 11-37

[5] RichaRd C. BROWN, Michael PluM, An Opial-type inequality with an integral boundary condition, Preprint 2003

[6] D. Cordero-ERAusquin, B. NAZARET, C. VILlani, A mass-transportation approach to sharp Sobolev and Gagliardo-Nirenberg inequalities, Adv. Math. 182 (2004), 307-332

[7] R. J. GARDNER, The Brunn-Minkowski inequality, Bull. Amer. Math. Soc. (N.S.) 39 (2002), 355-405

[8] M. GROMOv, Isoperimetric Inequalities in Riemannian Manifolds, Appendix in the book by V. D. Milman, G. Schechtman: Asymptotic Theory of finite dimensional normed spaces, Springer LNM \#1200, 1986

[9] N. LeVINSON, On an inequality of Opial and Beesack, Proc. Amer. Math. Soc. 15 (1964), 565-566

[10] ROBERT MCCANN, A convexity principle for interacting gases, Adv. in Math. 128 (1997), 153-179

[11] C. L. MaLlows, An even simpler proof of Opial's inequality, Proc. Amer. Math. Soc. 16 (1965), 173

[12] Cz. Olech, A simple proof of a certain result of Z. Opial, Annales Polonici Mathematici, 8 (1960), 61-63

[13] Z. OpIaL, Sur une inégalité, Annales Polonici Mathematici 8 (1960), 29-32

[14] R. N. Pederson, On an inequality by Opial, Beesack and Levinson, Proc. Amer. Math. Soc. 16 (1965), 174

[15] G. Talenti, Best constants in Sobolev inequality, Ann. Mat. Pura Appl. (4) 110 (1976), 353-372 